\title{
FAKTOR-FAKTOR YANG MEMPENGARUHI KEJADIAN KECELAKAAN KERJA PADA KARYAWAN DI PT. MARUKI INTERNASIONAL INDONESIA MAKASSAR TAHUN 2018
}

\author{
Nur Aisah Latuconsin ${ }^{1}$, Yahya Thamrin², Suharni A. Fachrin ${ }^{3}$ \\ ${ }^{1}$ Universitas Muslim Indonesia \\ ${ }^{2}$ Universitas Muslim Indonesia \\ ${ }^{3}$ Universitas Muslim Indonesia
}

Alamat korespondensi : (Itc_ay@yahoo.co.id/085343014358)

\begin{abstract}
ABSTRAK
Kesehatan dan keselamatan kerja merupakan salah satu faktor penting dalam kelancaran produksi sehingga program K3 harus diterapkan di perusahaan dan bukan hanya sekadar wacana. Kecelakaan kerja merupakan kecelakaan yang terjadi dalam lingkungan kerja yang dapat terjadi karena kondisi lingkungan kerja yang tidak aman ataupun karena human error. Tujuan penelitian ini adalah untuk menganalisis faktor determinan terjadinya kecelakaan kerja di PT. Maruki Internasional Indonesia Makassar Tahun 2018 ditinjau dari karakteristik responden, sikap kerja dan pengetahuan. Jenis penelitian yang digunakan adalah observasional analitik dengan pendekatan cross sectional study. Teknik pengambilan sampel dengan purposive sampling sebanyak 84 dengan menggunakan rumus slovin. Pengumpulan data dilakukan dengan observasi lingkungan kerja dan instrumen kuesioner. Hasil penelitian menunjukan bahwa ada hubungan antara variabel, sikap dan pengetahuan dengan kecelakaan kerja pada karyawan PT. Maruki Internasional Indonesia. Variable sikap dan pengetahuan harus mendapat perhatian khusus untuk mencegah kecelakaan kerja di PT. Maruki Internasional Indonesia. Diharapkan agar pihak perusahaan memberikan sosialisasi K3 dalam bentuk poster yang mudah dan jelas terbaca serta menarik perhatian. Perusahaan juga harus memperbaharui job safety analysis jika terjadi perubahan proses kerja.
\end{abstract}

Kata Kunci: kecelakaan kerja, pengetahuan, sikap

\section{PENDAHULUAN}

Kecelakaan kerja adalah salah satu dari sekian banyak masalah dibidang kesehatan kerja. Setiap kecelakaan kerja akan menimbulkan kerugian yang besar, baik itu kerugian material dan fisik. Kerugian yang disebabkan oleh kecelakaan kerja antara lain kerugian ekonomi dan kerugian non-ekonomi. Kerugian tersebut hanyalah sebagian kecil dari kecelakaan kerja. Dengan menerapkan usaha keselamatan dan kesehatan kerja maka kejadian kecelakaan kerja semestinya bisa dihindari (Ewin, dkk. 2016).

BPJS Ketenagakerjaan yang semula dikenal dengan nama PT Jamsostek mencatat di Indonesia tidak kurang dari 9 orang meninggal dunia akibat kecelakaan di tempat kerja setiap harinya. Data BPJS Ketenaga kerjaan tahun 2015 mencatat sebanyak 105.182 kasus kecelakaan kerja yang terjadi di Indonesia. 2.375 diantaranya mengakibatkan korban meninggal. Jumlah kecelakaan kerja yang tercatat merupakan fenomena gunung es, dimana adanya kemungkinan dilapangan menunjukkan tingkat kecelakaan kerja yang lebih tinggi namun tidak tercatat (BPJS Ketenagakerjaan, 2015).
Data Badan Penyelenggara Jaminan Sosial (BPJS) Ketenagakerjaan Wilayah Sulawesi dan Maluku memperlihatkan, kecelakaan kerja tiga tahun terakhir mengalami penurunan yaitu Pada 2015 terdapat 780 kasus, 2016 turun tipis 747 kasus sampai dengan bulan November 2016 akan tetapi mengalami kenaikan drastis pada 2017 menjadi 943 kasus (BPJS Sulsel, 2017).

Data BPJS Ketenagakerjaandari 150 kasus kecelakaan kerja pada periode Januari hingga Mei 2014 untuk wilayah Sulawesi Selatan $11,3 \%$ di antaranya terjadi di PT. Maruki International Indonesia, kasus kecelakaan tersebut berupa kecelakaan kerja ringan seperti kejadian tangan teriris, terpotong, dll, dan kejadian tersebut diasumsikan terjadi karena penerapan K3 yang belum maksimal di tempat kerja diantaranya perilaku-perilaku pekerja yang tidak sesuai standar K3 (Unsafe Action dan Unsafe Condition).

Berdasarkan data yang diperoleh di PT. Maruki Internasional Indonesia menunjukan bahwa jumlah seluruh karyawan adalah sebanyak 250 orang yang terdiri dari 174 orang laki-laki dan 76 orang perempuan. 
Data sekunder yang diperoleh dari klinik perusahaan PT. Maruki International Indonesia menunjukan bahwa penerapan Manajemen K3 belum mencapai Zero Accident. Hal dapat dilihat dari laporan kasus kecelakaan kerja. Pada tahun 2014 terdapat 21 kasus kecelakaan kerja, pada tahun 2015 terdapat 20 kasus kecelakaan kerja, pada tahun 2016 terdapat 10 kasus kecelakaan kerja serta pada tahun 2017 terdapat 12 kasus kecalakaan kerja.

Berdasarkan uraian pada latar belakang di atas, maka penelti mengangkat masalah penelitian tentang faktor - faktor apa saja berhubungan dengan kejadian kecelakaan kerja di PT. Maruki Internasional Indonesia Makasssar?

\section{BAHAN DAN METODE}

\section{Lokasi, Populasi, Sampel}

Penelitian ini dilaksanakan di PT. Maruki Internasional Indonesia yang berada di Jl. Kapasa Raya Kawasan Industri Makassar, Kapasa, Tamalanrea, Kota Makassar pada tanggal 10 oktober s/d 10 november 2018. Populasi yang digunakan pada penelitian ini adalah tenaga kerja yang bekerja di PT. Maruki Internasional Indonesia Makassar yang terdiri dari 106. Teknik pengambilan sampel pada penelitian ini menggunakan purposive sampling sebanyak 84 dengan menggunakan rumus slovin serta sampel dipilih berdasarkan beberapa kriteria yang sudah ditentukan sebelumnya oleh peneliti, kriteria tersebut meliputi :

1. Berada di tempat saat penelitian berlangsung

2. Bersedia menjadi responden dan memberikan informasi terkait penelitian ini

3. Telah bekerja di PT. Maruki Internasional Indonesia Makassar selama 1 tahun terakhir

4. Pekerja padabagian factory 1 , factory 2 dan factory 3

5. Tidak menderita penyaki tertentu yang dapat

\section{Pengumpulan Data}

1. Data Primer

Pengambilan data primer dilakukan dengan observasi lingkungan kerja dan hasil koesioner.

2. Data Sekunder

Data yang diperoleh dari perusahaan tempat penelitian dilakukan, seperti profil perusahaan dan pekerja serta sumber bacaan yang berhubungan dengan penelitian yang akan dilakukan. Peneliti mengguanakan data sekunder untuk memperkuat penemuan dan melengkapi informasi yang telah dikumpulkan melalui wawancara dan hasil koesioner.

\section{Pengolahan Data}

1. Editing

Mengecek kembali kebenaran dan kelengkapan data dari konsistensi dan relevan pengisian setiap jawaban kuesioner, kelengkapan pengisian, kejelasan tulisan, kejelasan makna jawaban,kesesuaian antar jawaban, dan kesalahan pengisian.

2. Coding

Memberi kode pada setiap variabel independen dan dependen pada kuesioner untuk mempermudah proses pemasukan dan pengolahan data selanjutnya. Mengkode jawaban adalah merubah data berbentuk huruf menjadi data berbentuk angka, sehingga mempermudah dalam mengentrydata serta menganalisis data tersebut.

3. Entry Data

Setelah data lengkap dan diberi kode maka kemudian data diproses agar bisa dianalisis. Proses ini dilakukan dengan memasukkan data dari kuesioner ke dalam program computer SPSS 17.

4. Cleaning

Memeriksa kembali data yang telah dientry, seperti jawaban yang missing, nilainilai ekstrim, atau data yang out of range. Hal ini dilakukan untuk memastikan data tersebut tidak ada yang salah, sehingga data tersebut telah siap diolah dan dianalisis.

\section{Analisis Data}

1. Analisis Univariat

Analisis univariat bertujuan untuk mendeskripsikan karakteristik masingmasing variabel yang telah diteliti, baik variabel independen (Umur, Jenis Kelamin, Tingkat Pendidikan, Pengetahuan, Masa Kerja, Sikap, Kepatuhan Terhadap Prosedur, Reward Dan Punishmen, sosialisasi $\mathrm{K} 3$, pengawasan) maupun dependen (kecelakaan kerja).

2. Analisis Bivariat

Analisis bivariat digunakan untuk mengetahui ada tidaknya hubungan variebel independen dengan variabel dependen. Adapun statistik uji yang digunakan adalah Chi Square dengan menggunakan test kemaknaan $5 \%$. Jika $P$ value $=0,05$ maka ada hubungan yang bermakna antara variabel independen dengan dependen. Sedangkan jika $P$ value $>0,05$ berarti tidak ada hubungan yang bermakna variabel independen dengan 
dependen.

3. Analisis Multivariat

Analisis Multivariat hanya akan menghasilkan hubungan antara dua variabel yang bersangkutan (variabel dependen dan independen). Untuk mengetahui hubungan lebih dari satu variabel dependen harus lagi dilanjutkan dengan melakukan analisis multivariate. Uji statistik yang biasa digunakan biasanya regresi berganda (multiple regression). Untuk mengetahui variabel independen yang mana yang lebih erat hubungannya dengan variabel dependen (Notoatmodjo, 2012).

\section{HASIL PENELITIAN}

1. Analisis Univariat

Tabel 1 Distribusi Responden Berdasarkan Karakteristik Responden Di PT. Maruki Internasional Indonesia Tahun 2018

\begin{tabular}{|c|c|c|}
\hline $\begin{array}{c}\text { Karakteristik } \\
\text { Responden }\end{array}$ & $\mathrm{Jml}$ & Presentase \\
\hline \multicolumn{3}{|l|}{ Umur } \\
\hline $\begin{array}{l}20-35 \\
\text { (Dewasa Muda) }\end{array}$ & 44 & 52,4 \\
\hline $\begin{array}{l}36-50 \\
\text { (Dewasa Tua) }\end{array}$ & 40 & 47,6 \\
\hline \multicolumn{3}{|l|}{ Jenis Kelamin } \\
\hline Laki-laki & 52 & 61,9 \\
\hline Perempuan & 32 & 38.1 \\
\hline \multicolumn{3}{|c|}{ Tingkat Pendidikan } \\
\hline SMP & 10 & 11,9 \\
\hline SMA & 61 & 72,6 \\
\hline S1 & 13 & 15,5 \\
\hline \multicolumn{3}{|l|}{ Masa Kerja } \\
\hline $4-6$ thn & 46 & 54,8 \\
\hline $7-10$ thn & 23 & 27,4 \\
\hline$>10$ thn & 15 & 17,9 \\
\hline
\end{tabular}

Berdasarkan tabel 5.2 dapat dilihat bahwa responden yangmemiliki usia kategori dewasa mudaberjumlah 44 orang $(52,4 \%)$ dan dewasa tua berjumlah 40 orang $(47,6 \%)$. Responden yang berjenis kelamin laki-laki lebih berjumlah 52 orang $(61,9 \%)$ dan perempuan berjumlah 32 orang $(38.1 \%)$. Responden yang memiliki tingkat pendidikan SMP berjumlah 10 orang $(11,9)$, tingak pendidikan SMA berjumlah 61 orang $(72,6 \%)$ dan tingkat pendidikan S1 berjumlah 13 orang (15,5\%). Responden yang memiliki kategori masa kerja $4-6$ tahun berjumlah 46 orang $(54,8 \%), \quad 7-10$ tahun berjumlah 23 orang $(27,4 \%)$ dan kategori masa kerja $>10$ tahun berjumlah 15 orang $(17,9 \%)$
2. Analisis Bivariat

Tabel 2 Hubungan Faktor Sikap Dengan Kecelakaan Kerja Di PT. Maruki Internasional Indonesia Tahun 2018

\begin{tabular}{|c|c|c|c|c|c|c|}
\hline \multirow{2}{*}{$\begin{array}{c}\text { Faktor } \\
\text { Sikap }\end{array}$} & \multicolumn{4}{|c|}{ Kecelakaan Kerja } & \multirow{2}{*}{ Total } \\
\cline { 2 - 5 } & \multicolumn{2}{|c|}{ Tidak } & \multicolumn{2}{|c|}{ Ya } & \\
\hline Negatif & 4 & 11,8 & 30 & 88,2 & 34 & 100 \\
\hline Positif & 26 & 52,0 & 24 & 48,0 & 50 & 100 \\
\hline Jumlah & 30 & 35,7 & 54 & 64,3 & 84 & 100 \\
\hline \multicolumn{5}{|c|}{$p$ value $=0,000$} \\
\hline
\end{tabular}

Berdasarkan pada tabel 2 diketahui bahwa pekerja yang mengalami kecelakaan kerja pada kategori sikap negative sebanyak 30 orang $(88,2 \%)$ dan pada kategori sikap positif sebanyak 24 orang $(48,01 \%)$ sedangkan pekerja yang tidak mengalami kecelakaan kerja pada kategori sikap negatif sebanyak 4 orang $(11,8 \%)$ dan pada kategori sikap positif sebanyak 26 orang (52\%). Hal ni dapat dilihat bahwa responden yang memiliki sikap negatif lebih banyak mengalami kecelakaan kerja. Hasil uji Chi-Square menunjukan ada hubungan yang bermakna antara sikap dengan kecelakaan kerja. ( $P$ value 0,000 ).

Tabel 3 Hubungan Faktor Pengetahuan Dengan Kecelakaan Kerja Di PT. Maruki Internasional Indonesia Tahun 2018

\begin{tabular}{|c|c|c|c|c|c|c|}
\hline \multirow{2}{*}{$\begin{array}{c}\text { Faktor } \\
\text { Pengetahuan }\end{array}$} & \multicolumn{4}{|c|}{ Kecelakaan Kerja } & \multirow{2}{*}{ Total } \\
\cline { 2 - 6 } & \multicolumn{2}{|c|}{ Tidak } & \multicolumn{2}{|c|}{ Ya } & \multicolumn{1}{c}{} \\
\cline { 2 - 6 } & $\mathrm{n}$ & $\%$ & $\mathrm{n}$ & $\%$ & $\mathrm{n}$ & $\%$ \\
\hline Rendah & 7 & 15,6 & 38 & 84,4 & 45 & 100 \\
\hline Tinggi & 23 & 59,0 & 16 & 41,0 & 39 & 100 \\
\hline Jumlah & 30 & 35,7 & 54 & 64,3 & 84 & 100 \\
\hline \multicolumn{5}{c}{$p$ Value $=0,000$} \\
\hline
\end{tabular}

Berdasarkan pada tabel 3 diketahui bahwa 38 orang $(84,4 \%)$ yang berpengetahuan rendah pernah mengalami kecelakaan kerja dan berpengetahuan tinggi sebanyak 16 orang $(41,0 \%)$ sedangkan yang berpengetahuan rendah tidak mengalami kecelakaan kerja sebanyak 7 orang $(15,6 \%)$ dan 23 orang $(59,0 \%)$ pada responden berpengetahuan tinggi. Hasil uji Chi-Square menunjukan ada hubungan yang bermakna antara pengetahuan dengan kecelakaan kerja. $(P$ value 0,000 ).

3. Analisis Multivariat

Analisis multivariat menunjukan variabel yang berhubungan dengan kecelakaan kerja $(P$ value $<0,05)$. Variabel yang berhubungan dengan kecelakaan 
kerja pada PT. Maruki Internasional Indonesia ialah variabel pengetahuan dan sikap selanjutnya untuk variabel yang paling dominan berhubungan dengan kecelakaan kerja dapat dilihat dari nilai OR. Tabel 5.16 menunjukkan bahwa variabel pengetahuan yang paling dominan berhubungan dengan kecelakaan kerja. Hasil analisis didapatkan nilai OR dari variabel pengetahuan sebesar 9,871, artinya orang yang memiliki pengetahuan lebih rendah mempunyai peluang 9,871 kali untuk mengalami kecelakaan kerja.

\section{PEMBAHASAN}

1. Pengaruh Sikap Dengan Kecelakaan Kerja Pada Karyawan PT. Maruki Internasional Indonesia.

Berdasarkan hasil penelitian dilihat bahwa responden yang memiliki sikap positif lebih banyak $50(59,5 \%)$ orang dari pada responden yang memiliki sifat negatif dengan jumlah 34 orang $(40,5)$. Selain itu berdasarkan hasil penelitian pada tabel 5.9 responden yang memiliki sikap negatif lebih banyak mengalami kecelakaan sebanyak 30 orang dibandingkan dengan responden yang mengalami sikap positif sebanyak 25 orang.

Hasil analisis statistik menunjukkan nilai probabilitas ( $P$ value000), yang berarti jika nilai $(P$ value 0,000$)>$ a 0,05 dimana Ha diterima, maka ada pengaruh antara sikap kerja dengan kecelakaan kerja pada karyawan PT. Maruki Internasional Indonesia. Hal ini menunjukan bahwa semakin negatif sikap responden maka akan semakin tinggi kecelakaan kerja dan sebaliknya, semakin positif sikap responden maka akan semakin rendah angka kecelakaan kerja.

Penelitian ini sejalan dengan penelitian yang dilakukan oleh Barathi (2018) yang menunjukan hasil uji chisquare pearson diperoleh nilai $P$ value $0,021<0,05$, menunjukan bahwa terdapat hubungan yang signifikan antara sikap dengan kecelakaan kerja. Pada hasil penelitian diketahui bahwa sikap yang paling banyak tanggapan negatif yaitu sikap pekerja terhadap penggunaan APD sewaktu bekerja, pekerja merasa tidak nyaman bekerja menggunakan APD dan merasa terganggu menggunakan APD.

Menurut Notoatmojo tahun (2010) sikap adalah respon yang tidak teramati secara langsung yang masih tertutup dari seseorang terhadap stimulasi atau objek. Penelitian ini sesuai dengan pendapat ILO (1998) pada Indah yang menyatakan bahwa sikap seseorang dapat berubah melalui tekanan keselamatan selama kursus pelatihan dan pendidikan. Sehingga apabila pengetahuan pekerja tentang faktor-faktor penyabab kecelakaan kerja baik maka dapat menimbulkan sikap yang baik pula. Jika seseorang bersikap positif akan cenderung berperilaku yang positif dan juga sebaliknya.

Pekerja yang memiliki sikap positif akan merasa bahwa pencegahan terhadap kejadian tidak diinginkan seperti kecelakaan kerja. Mereka akan merasa dan berpendapat bahwa prosedur dan peraturan keselamatan dan kesehatan kerja dibuat dan dibentuk untuk melindungi dan meningkatkan produktivitas kerja. Sikap yang positif dapat menimbulkan perilaku yang positif sehingga dapat menghindari kecelakaan kerja. Sebaliknya pekerja yang memiliki sikap negatif akan cenderung tidak peduli terhadap lingkungan dan bahaya disekitarnya. Mereka merasa dan berpendapat bahwa prosedur dan peraturan keselamatan dan kesehatan kerja hanya dibuat dan dibentuk untuk kepentingan perusahaan saja dan hanya membebani pekerja dengan beberapa peraturan yang menghambat kinerja. Sehingga pekerja yang memiliki sikap negatif tidak mampu untuk melakukan pencegahan terhadap kecelakaan kerja.

2. Pengaruh Pengetahuan Dengan Kecelakaan Kerja Pada Karyawan PT. Maruki Internasional Indonesia.

Berdasarkan hasil penelitian dapat dilihat bahwa responden yang memiliki tingkat pendidikan rendah sebanyak 45 $(53,6 \%)$ lebih banyak dari responden yang memiliki tingkat pendidikan tinggi yaitu 39 orang $(46,4 \%)$. Selain itu berdasarkan hasil penelitian pada tabel 5.10 menunjukan bahwa responden yang memiliki pengetahuan rendah lebih banyak mengalami kecelakaan kerja yaitu sebanyak 38 orang dibandingkan responden yang memiliki pengetahuan tinggi yaitu sebanyak 16 orang.

Hasil analisis statistik menunjukkan nilai probabilitas ( $P$ value000), yang berarti jika nilai $(P$ value 0,000$)>$ a 0,05 dimana Ha diterima, maka ada pengaruh antara pengetahuan dengan kecelakaan kerja pada karyawan PT. Maruki Internasional Indonesia. Hal ini menunjukan bahwa semakin tinggi pengetahuan pekerja maka semakin tinggi upaya untuk menghindari kecelakaan kerja. 
Penelitian yang sama juga dilakukan oleh Barathi (2018) yang menunjukan hasil uji chi-square diperoleh nilai $P$ value 0,035 $=0,05$ menunjukkan bahwa terdapat hubungan yang nyata antara pengetahuan dengan kecelakaan kerja. Yang dimana responden yang memiliki pengetahuan rendah lebih banyak mengalami kecelakaan kerja dibandingkan dengan pekerja yang memiliki pengetahuan tinggi.

Dalam penelitian ini menyimpulkan bahwa pengetahuan mempengaruhi kejadian kecelakaan kerja pada karyawan PT. Maruki Internasional Indonesia. Hal ini dikarenakan pekerja yang memiliki pengetahuan tinggi akan mampu membedakan dan mengetahui bahaya disekitarnya serta dapat melakukan pekerjaan sesuai dengan prosedur yang ada karena mereka sadar akan resiko yang diterima sehingga kecelakaan kerja bisa dihindari. Sebaliknya pekerja yang meiliki pengetahuan rendah akan cenderung mengabaikan bahaya disekitarnya dan tidak melakukan pekerjaan sesuai prosedur karena ketidaktahuan akan resiko yang akan diterima. Hal ini dikarenakan ketidaktahuan dan ketidaksadaran pekerja akan pentingnya prosedur dan peraturan dalam bekerja guna melindungi pekerja itu sendiri.

\section{KESIMPULAN}

1. Ada hubungan antara sikap dengan kecelakaan kerja pada karyawan PT. Maruki Internasional Indonesia.

2. Ada hubungan antara pengetahuan dengan kecelakaan kerja pada karyawan PT. Maruki Internasional Indonesia.

\section{SARAN}

1. Meningkatkan pengetahuan dengan memberikan pelatihan kepada karyawan.

2. Meningkatkan sosialisasi K3 dalam bentuk poster yang mudah dibaca, menarik perhatian dan jelas dibaca. Serta memperbaharui job safety analysis jika terjadi perubahan proses kerja.

\section{DAFTAR PUSTAKA}

Agiviana, A. P. (2015). Analisis Pengaruh Persepsi, Sikap, Pengetahuan dan Tempat Kerja terhadap Perilaku Keselamatan Karyawan: Studi pada Perusahaan PT MuliaGlass Container Division. Skripsi:

Aswadi. 2012, Analisis Faktor-Faktor Yang Memepengaruhi Kecelakaan Kerja Karyawan Bagian Drilling Pada Pt. Saripari Pertiwi Abadi (Spa) Kecamatan Mandau Kabupaten Bengkalis (online), (http://repository.uinsuska.ac.id/id/eprint/1534, Diakses : 30 Agustus 2018).

Barathi Raja, 2018. Faktor Yang Berhubungan Dengan Kecelakaan Kerja Di Pt. Sumber Karindo Sakti Tebing Tinggi (online), (http://repositori.usu.ac.id/bitstream/handle/123456789/2812/131000739.pdf?sequence=1\&isAllowed=y, diakses : 30 agustus 2018).

Dwi Sapta, Dewi Husmaryuli, 2015. Kejadian Kecelakaan Kerja Pekerja Aspal Mixing Plant (Amp) \& Batching Plant Di $\quad$ PtLwp $\quad$ Pekanbaru $\quad$ Tahun $2015 \quad$ (online), (http://jurnal.fkm.unand.ac.id/index.php/jkma/article/download/199/213, diakses : 30 agustus 2018).

Dornaria, Dkk. 2016. Faktor - Faktor Yang Berhubungan Dengan Kecelakaan Kerja Pada Buruh Angkut Sampah Di Kota Manado (online), (https://ejournalhealth.com/index.php/CH/article/download/14/14, diakses : 30 agustus 2018) 